\title{
Uniform and Intense Cooling During Hardening Steel in Low Concentration of Water Polymer Solutions
}

\author{
Nikolai Kobasko \\ Intensive Technologies Ltd, Kyiv, Ukraine
}

Email address:

nkobasko@gmail.com

\section{To cite this article:}

Nikolai Kobasko. Uniform and Intense Cooling During Hardening Steel in Low Concentration of Water Polymer Solutions. American Journal of Modern Physics. Vol. 8, No. 6, 2019, pp. 76-85. doi: 10.11648/j.ajmp.20190806.11

Received: October 23, 2019; Accepted: November 19, 2019; Published: November 25, 2019

\begin{abstract}
The possibility of decreasing water polymer concentration, decreasing alloy elements in steel, decreasing distortion of steel parts, and increasing service life of machine components and tools during quenching is widely discussed in this paper based on achievements of modern physics. Instead of quenching alloy steel in oils or high concentration of water polymer solutions, the accelerated quench process of optimal hardenability steel in water low concentration of inverse solubility polymers is proposed. Physics of the new approach and new technologies is explained by the author. The creation of a thin polymeric insulating layer during quenching steel in low concentration of inverse solubility polymers decreases initial heat flux density below its critical value that is reason for absence the film boiling process. Due to this fact, full film boiling during quenching is completely absent allowing use optimal hardenability steel instead of alloy steels containing costly alloy elements. Accelerated cooling provided by low concentration of water polymer solution results in creation of high surface compression residual stress, and super strengthening of material that in turn increases service life of machine components and tools. It is underlined in the paper that along with the use of a thin polymeric insulating layer, the resonance effect can be used for destroying the full film boiling process based on implementation different kinds of hydrodynamic emitters. The proposed new technology saves materials, increases service life of steel parts, and improves environment condition in heat treating industry. The patented technologies and processes can be used by engineers and scientists. and can bring great benefits if widely implemented in the practice.
\end{abstract}

Keywords: Insulating Layer, Heat Flux Decrease, Film Boiling Elimination, Intense and Uniform Quenching, Optimal Hardened Layer, Alloying and Concentration Decrease, Benefits

\section{Introduction}

For the wide implementation of intensive quenching processes into practice, two companies were established in 1999 and 2000 dealing with intensive quenching processes. The first company was established in 1999 in Akron, Ohio, USA and its name is IQ Technologies Inc (IQT). The second company was established in 2000 in Kyiv, Ukraine and its name is Intensive Technologies Ltd (ITL). A continuous cooperation between both companies has been lasting since 2000. The aim of IQT is designing equipment and commercialization of intensive quenching processes while ITL pays its main attention to academic investigations and designing appropriate software for controlling and governing intensive quenching processes in the practice. The IQT company made a great progress in hardening the small and average machine components and tools while ITL is developing new technologies for more larger steel components and tools which cannot be quenched in developed by IQT fixtures. Currently, there are several Ukrainian Patents which make a green pass for their implementation in the USA if properly developed and tested [1-3]. This paper discusses the physics of accelerated cooling in water solutions of low concentration of polymers and provides possibility of intense hardening of large steel parts like wind gears, rollers, large shafts and rotors, made of optimal hardenability steel to save energy, materials, increase their service life and improve environment condition. 


\section{Intense Quenching When Cooling in Low Concentration of Water Polymer Solutions}

As known, the real heat transfer coefficient during transient nucleate boiling process is evaluated as a ratio of the heat flux density produced by bubbles to the overheat of the boundary layer [4-6], i.e.

$$
\alpha_{n b}=\frac{q}{T_{s f}-T_{s}} .
$$

Here $\alpha_{n b}$ is the real HTC during transient nucleate boiling process; $\alpha_{e f}$ is an effective HTC; q is heat flux density; $T_{s f}$ is surface temperature; $T_{s}$ is saturation temperature; $T_{m}$ is bath temperature.

In heat treating industry, historically, the heat transfer coefficient (HTC) during transient nucleate boiling process is evaluated as:

$$
\alpha_{e f}=\frac{q}{T_{s f}-T_{m}}, T_{m}<T_{s} .
$$

It cannot be used for temperature gradients calculation. As seen from Table 1, the real HTC is almost 7 times larger as compared with the effective HTC $[4,6]$.

Table 1. Ratio of real HTC to effective HTC versus temperature of water.

\begin{tabular}{llllllll}
\hline Temperature, ${ }^{\circ} \mathbf{C}$ & $\mathbf{1 5}$ & $\mathbf{2 0}$ & $\mathbf{3 0}$ & $\mathbf{4 0}$ & $\mathbf{6 0}$ & $\mathbf{8 0}$ & $\mathbf{9 0}$ \\
\hline$\alpha_{\text {real }} / \alpha_{\text {eff }}$ & 7.07 & 6.71 & 6.00 & 5.29 & 3.86 & 2.43 & 1.71 \\
$\alpha_{\text {real }} / \alpha_{\text {eff }}, \%$ & 707 & 671 & 600 & 529 & 386 & 243 & 171 \\
\hline
\end{tabular}

According to author [4], the average heat flux density $q$ during nucleate boiling is proportional to the cube of temperature difference $\Delta T_{S}=T_{s f}-T_{S}$ :

$$
q \approx \Delta T_{S}^{3}
$$

that is why the small overheat $\Delta T_{S}=T_{s f}-T_{S}$ can support a
Table 2 shows the real heat transfer coefficients in $\mathrm{W} / \mathrm{m}^{2} \mathrm{~K}$ which are responsible for developing temperature gradients during quenching of steel parts. Calculations of HTCs were made for maximal critical heat flux density of water salt solutions which was equal to $15 \mathrm{MW} / \mathrm{m}^{2}$ [4]. Dimensionless correlations of authors $[4,6]$ were used for this purpose. huge heat flux density from the very beginning of cooling.

Table 2. Real HTCs in $\mathrm{W} / \mathrm{m}^{2} \mathrm{~K}$ during nucleate boiling process depending on the temperature of water solution when heat flux density is $15 \mathrm{MW} / \mathrm{m}^{2}$.

\begin{tabular}{lll}
\hline Temperature of water solution & Tolubinsky & Shekriladze \\
\hline 10 & 152248 & 176546 \\
20 & 193929 & 243641 \\
40 & 224989 & 241615 \\
60 & 271273 & 271323 \\
\hline
\end{tabular}

Results of calculations presented in Table 2 actually are experimental data because dimensionless equations of Tolubinsky and Kutateladze are based on thousand of accurate experiments $[4,5]$.

As seen from Table 2, the real HTCs are very large when heat flux density approaches the critical value $15 \mathrm{MW} / \mathrm{m}^{2}$. It means that in the Inconel 600 standard probe $12.5 \mathrm{~mm}$ in diameter and in quench steel parts maximal temperature gradients are formed because Biot number $\mathrm{Bi}$ tends to infinity (see Table 3).

Table 3. Biot numbers and criterion of non-uniformity of coong through section of steel parts versus heat transfer coefficients.

\begin{tabular}{lllll}
\hline $\mathbf{H T C},\left(\boldsymbol{W} / \mathbf{m}^{2} \boldsymbol{K}\right)$ & $\boldsymbol{R}(\boldsymbol{m})$ & $\boldsymbol{B i}$ & $\boldsymbol{B i}_{\boldsymbol{V}}$ & $\boldsymbol{\Psi}$ \\
\hline \multirow{3}{*}{1000} & 0.05 & 2.5 & 0.865 & 4.325 \\
& 0.25 & 12.5 & 8.650 & 0.58 \\
& 0.50 & 25 & 1.730 & 0.195 \\
2000 & 0.05 & 5.0 & 8.650 & 0.104 \\
& 0.25 & 25 & 2.595 & 0.39 \\
3000 & 0.50 & 50 & 12.97 & 0.104 \\
& 0.05 & 7.5 & 25.95 & 0.29 \\
4000 & 0.25 & 37.5 & 3.460 & 0.073 \\
10000 & 0.50 & 75 & 17.30 & 0.037 \\
$\infty$ & 0.05 & 10 & 34.60 & 0.24 \\
\end{tabular}

It is very important to calculate temperature gradient during quenching small and large steel parts in liquid media.
As an example, let's consider quenching truck semi-axles 40 $\mathrm{mm}(0.04 \mathrm{~m})$ in thickness which is cooled in water flow of 8 
$\mathrm{m} / \mathrm{s}$ and large roller $1 \mathrm{~m}$ in diameter which is cooled in still water at $30^{\circ} \mathrm{C}$ where natural convection takes place. Cooling steel parts in water flow was discussed in previous published papers [7, 8], and [9]. Heat transfer coefficients for quenching cylindrical steel parts in water flow in round fixture one can find in Refs. [7, 10] (see Table 4).

Table 4. Average convective heat transfer coefficients $\left(\mathrm{W} / \mathrm{m}^{2} \mathrm{~K}\right)$ depending on water flow speed and water temperature in channel [7].

\begin{tabular}{|c|c|c|}
\hline $\mathrm{W},(\mathrm{m} / \mathrm{s})$ & $20^{\circ} \mathrm{C}$ & $30^{\circ} \mathrm{C}$ \\
\hline 0 & 802 & 1017 \\
\hline 0.5 & 2890 & 3200 \\
\hline 2 & 8770 & 9700 \\
\hline 8 & 26580 & 29400 \\
\hline
\end{tabular}

The natural convection during quenching large steel parts in still water is calculated using well known Eq. (4) [10]:

$$
\alpha_{\text {conv }}=0.135 \lambda\left(\frac{g \beta \Delta T}{a v}\right)^{1 / 3}
$$

which provides $802\left(\mathrm{~W} / \mathrm{m}^{2} \mathrm{~K}\right)$ and $1017\left(\mathrm{~W} / \mathrm{m}^{2} \mathrm{~K}\right)$ values for water $20^{\circ} \mathrm{C}$ and $30^{\circ} \mathrm{C}$ (see Table 4). Using these accurately calculated data, we'll investigate temperature gradients in semi-axle and roller during their hardening in water flow and still water. Since during quenching HTCs are a little bit variable, depending on size of semi- axle and water temperature, we'll use $1000\left(\mathrm{~W} / \mathrm{m}^{2} \mathrm{~K}\right)$ for quenching in still water and $25000\left(\mathrm{~W} / \mathrm{m}^{2} \mathrm{~K}\right)$ for quenching in water flow. For calculating temperature gradients during quenching of steel parts, one can use universal correlation $(5)[11,12]$ :

$$
\psi=\frac{\bar{T}_{s f}-T_{m}}{\bar{T}_{V}-T_{m}}=\frac{1}{\left(B i_{V}{ }^{2}+1.437 B i_{V}+1\right)^{0,5}}
$$

Therefore, during quenching semi - axle in water flow with the intensity of cooling $25000\left(\mathrm{~W} / \mathrm{m}^{2} \mathrm{~K}\right)$ and roller in still water with the intensity of cooling $1000\left(\mathrm{~W} / \mathrm{m}^{2} \mathrm{~K}\right)$, the value $\psi$ is $\frac{\bar{T}_{s f}-T_{m}}{\bar{T}_{V}-T_{m}}=0.105$ for both cases and is the same because for semi - axle

$$
B i=\frac{25000 \mathrm{~W} / \mathrm{m}^{2} \mathrm{~K} \times 0.02 \mathrm{~m}}{20 \mathrm{~W} / \mathrm{mK}}=25
$$

and for large roller

$$
B i=\frac{1000 \mathrm{~W} / \mathrm{m}^{2} \mathrm{~K} \times 0.5 \mathrm{~m}}{20 \mathrm{~W} / \mathrm{mK}}=25
$$

For both steel parts surface temperature during immersion into quenchant drops immediately to the same value $T_{s f}$ if initial austenitizing temperature and bath temperature are the same. Assume that initial temperature is $840^{\circ} \mathrm{C}$ and bath temperature is $20^{\circ} \mathrm{C}$, then average volume temperature is $410^{\circ} \mathrm{C}$. According to Eq. (5), the average surface temperature is $T_{s f}=61^{\circ} C$. Cooling semi - axle in water flow $8 \mathrm{~m} / \mathrm{s}$ provides very intensive quenching creating huge temperature gradient in semi - axle. The same huge temperature gradient is formed during quenching of large roller in still water if film boiling is absent. It means that for big roller during quenching in still water, the cooling process for it is also very intensive quenching. This conclusion is extremely important because customers don't need very expensive complicated equipment for performing intensive quenching. The cooling process of large steel parts can be performed just in large quench water tanks without complicated and costly equipment. However, there is a trick here. During immersion large steel parts into liquid, developed film boiling starts immediately, making cooling process slow. One should eliminate film boiling process from the very beginning of cooling prior to provide intensive quenching for large steel parts in still water. Very cheap and simple method of eliminating film boiling process during quenching is discussed below.

\section{Elimination Film Boiling Process by Creation a Thin Surface Insulating Layer}

The idea on elimination film boiling during quenching via creation artificial surface insulating layer before quenching was forwarded by authors in 1987 [13]. In 1996 authors [14] discovered that low concentration (1\%) of inverse solubility polymer in water, provides very intensive and uniform cooling even during testing of silver spherical probe $20 \mathrm{~mm}$ in diameter. In 2012 author [15] explained this unusual fact by considering Eq. (6):

$$
\begin{aligned}
q_{\text {in }}= & \frac{q_{o}}{\left(1+\frac{\delta}{R} \frac{\lambda}{\lambda_{\text {coat }}}\right)} \\
\Delta & =\left(1+\frac{\delta}{R} \frac{\lambda}{\lambda_{\text {coat }}}\right)
\end{aligned}
$$

In this paper the initial heat flux density during quenching of cylindrical specimen is considered which was received by solving inverse problem (IP). Results of calculation are presented in Figure 1. 


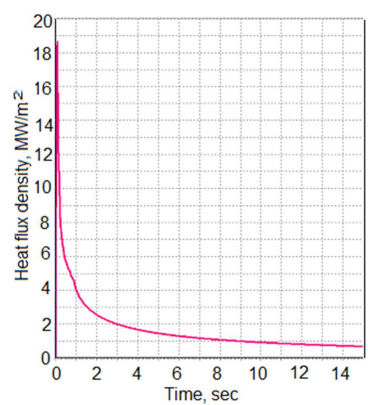

Figure 1. Heat flux density versus time during quenching of cylindrical probe $50 \mathrm{~mm}$ in diameter in water salt solution of optimal concentration at $20^{\circ} \mathrm{C}$

Let's consider now how the thickness of insulating polymeric layer $\delta$ decreases initial heat flux density $\mathrm{q}_{\mathrm{in}}$. Table 5 provides the value $\Delta$ depending on thickness of the insulating layer $\delta$.

Table 5. The value of $\Delta$ depending on thickness of insulating layer $\delta$ in microns when quenching cylindrical steel probe $50 \mathrm{~mm}$ in diameter.

\begin{tabular}{lllll}
\hline $\boldsymbol{\delta}$, microns & $\mathbf{2 5}$ & $\mathbf{5 0}$ & $\mathbf{7 5}$ & $\mathbf{1 0 0}$ \\
\hline$\Delta$ & 1.2 & 1.4 & 1.6 & 1.8 \\
\hline
\end{tabular}

Table 6 shows decrease of maximal initial heat flux density $\mathrm{q}_{\max }$ depending on thickness of insulating layer $\delta$. It was assumed that thermal conductivity of insulating layer was $0.2 \mathrm{~W} / \mathrm{mK}$.

Table 6. Initial maximal heat flux density $q\left(\mathrm{MW} / \mathrm{m}^{2}\right)$ versus thickness of the insulating layer $\delta$ during quenching of cylindrical steel probe $50 \mathrm{~mm}$ in diameter in cold liquid.

\begin{tabular}{llllll}
\hline $\boldsymbol{\delta}$ in microns & $\mathbf{0}$ & $\mathbf{2 5}$ & $\mathbf{5 0}$ & $\mathbf{7 5}$ & $\mathbf{1 0 0}$ \\
\hline $\mathrm{q}$ in $\mathrm{MW} / \mathrm{m}^{2}$ & 19 & 15.8 & 13.6 & 11.9 & 10.5 \\
\hline
\end{tabular}

Tolubinsky studied extreme transient nucleate boiling processes and he came to conclusion that the well known ratio (7).

$$
\frac{q_{c r 2}}{q_{c r 1}}=0.2
$$

is true during conventional processes. In extreme condition during shock boiling the well known ratio (7), depending on extreme cooling rate, can be [4]:

$$
\frac{q_{c r 2}}{q_{c r 1}}=0.05
$$

For conventional processes, according to Tolubinsky and Kutateladze [4, 5], the first critical heat flux densities for water depending on the underheat $\vartheta_{u h}=T_{s}-T_{m}$ are provided in Table 7.

Table 7. The first critical heat flux density $q_{c r 1}\left(M W / m^{2}\right)$ versus underheating at normal atmosphere pressure for water [4, 5].

\begin{tabular}{lllllll}
\hline $\begin{array}{l}\text { Underheat } \\
\boldsymbol{\vartheta}_{\boldsymbol{u h}}=\boldsymbol{T}_{\boldsymbol{S}}-\boldsymbol{T}_{\boldsymbol{m}}\end{array}$ & $\mathbf{s}$ & $\mathbf{2 0}$ & $\mathbf{4 0}$ & $\mathbf{6 0}$ & $\mathbf{8 0}$ & $\mathbf{1 0 0}$ \\
\hline Tolubinsky & 1.27 & 2.40 & 3.57 & 4.72 & 5.90 & 7.06 \\
Kutateladze & 1.185 & 2.25 & 3.33 & 4.40 & 5.50 & 6.60 \\
\hline
\end{tabular}

Assume that bath temperature in quenching tank is $40^{\circ} \mathrm{C}$ providing underheat $60^{\circ} \mathrm{C}$. If during quenching shock nucleate boiling takes place, then according to Eq. (8) and Table 7, the first critical heat flux density is approximately equal to $q_{c r 1}=4.40 \mathrm{MW} / \mathrm{m}^{2} \times 4=17.6 \mathrm{MW} / \mathrm{m}^{2}$. Maximal initial heat flux density during quenching cylindrical probe $50 \mathrm{~mm}$ in diameter without insulating layer is $19 \mathrm{MW} / \mathrm{m}^{2}$. During quenching in low concentration of inverse solubility polymers in water, providing insulating layer 25 micron, initial heat flux density reduces to $15.8 \mathrm{MW} / \mathrm{m}^{2}$ that is below the critical value $17.6 \mathrm{MW} / \mathrm{m}^{2}$. It means that film boiling is completely absent. In this case, uniform and intensive quenching starts from the very beginning of cooling. Here, it is explained why during quenching in water solutions of inverse solubility polymers film boiling is completely absent. Experimental data supporting this idea were published in 1996 in Ref. [14] (see Table 8).

Table 8. Experimental data on the influence of the PAG concentration on the duration of film- and nucleate boiling processes during quenching of silver spherical probe $20 \mathrm{~mm}$ in diameter in water and water solutions at $20^{\circ} \mathrm{C}$ [14].

\begin{tabular}{llll}
\hline Concentration, $\%$ & $\boldsymbol{\tau}_{\boldsymbol{F} \boldsymbol{B}}, \mathbf{s}$ & $\boldsymbol{\tau}_{\boldsymbol{n} \boldsymbol{b}}, \mathbf{s}$ & $\boldsymbol{v}_{\boldsymbol{m a x}},{ }^{\mathbf{0}} \mathbf{C} / \mathbf{s}$ \\
\hline Water & 7 & 2 & 231 \\
PAG, $1 \%$ & 0.2 & 2.1 & 674 \\
3 & 1.5 & 2.5 & 467 \\
10 & 1.8 & 4 & 336 \\
20 & 2.6 & 6 & 251 \\
\hline
\end{tabular}

Authors [16] used the same idea for eliminating film boiling process during quenching steel parts in mineral oil adding to it low amount of PIB. Figure 2 clearly shows decreasing duration of film boiling process when concentration of PIB in mineral oil increases and disappear completely at concentration 3\% PIB in mineral I-20A oil.

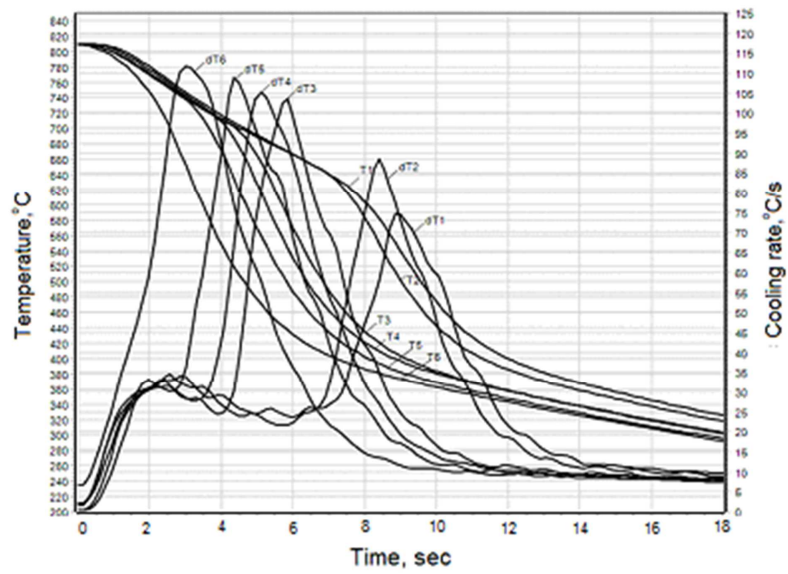

Figure 2. Curves of temperature (T) and cooling rate (dT) of a cylindrical probe in PIB 2400 solutions in I-20A oil at $50^{\circ} \mathrm{C}$, concentration, \% weight [16]: $1-0.0 ; 2-0.5 ; 3-1.0 ; 4-1.5 ; 5-2.0 ; 6-3.0$.

It means that insulating layer is excellent tool for eliminating film boiling processes during quenching steel parts in different liquid quenchants. 


\section{Difference Between IQ - 2 and IQ - 3 Processes}

For practical use, it is very important to find out what is difference between IQ - 2 and IQ - 3 processes when switching from one to another depending on their size and condition of cooling. As known, when initial austenitizing temperature is fixed at $850^{\circ} \mathrm{C}$ and bath temperature at $20^{\circ} \mathrm{C}$, the duration of transient nucleate boiling process can be calculated by simplified Eq. (9) $[17,18]$ :

$$
\tau_{n b}=\Omega k_{F} \frac{D^{2}}{a}
$$

In this case, the value $\Omega$ is only a function of the convection Biot number $\mathrm{Bi}[19,20]$ and duration of transient nucleate boiling process is formulated as follows. Duration of transient nucleate boiling is proportional to square of thickness of steel part, inversely proportional to thermal diffusivity of steel, depends on configuration of steel part quenched and cooling characteristics of quenchant if austenitizing and bath temperatures are fixed. During transient nucleate boiling process the surface temperature of steel part maintains at the level of boiling point of a liquid insignificantly differs from it. The established new characteristics were used for developing austempering process via cold liquids [6] and also for reconstruction of surface temperature during nucleate boiling and for estimation the cooling difference between IQ-2 and IQ - 3 processes (see Figure 3 a), b)).

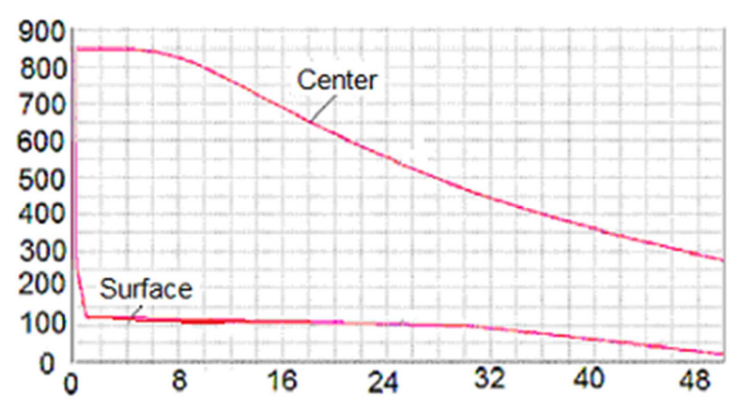

a)

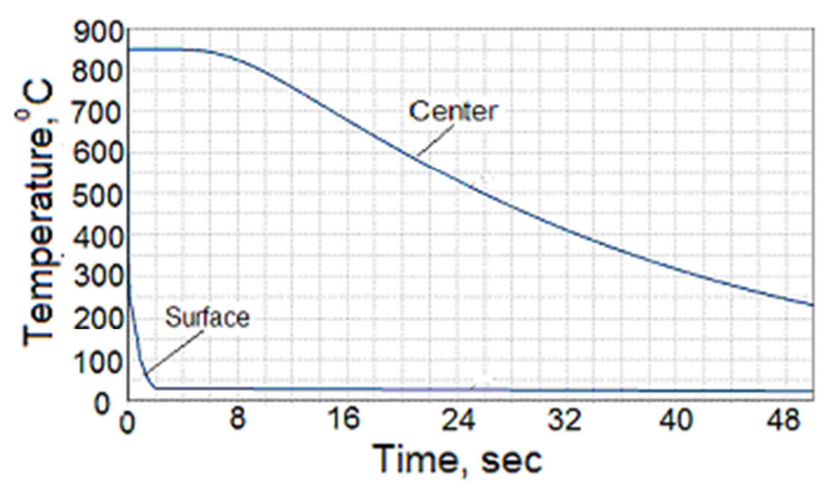

b)

Figure 3. Temperatures difference between $I Q-2$ and $I Q-3$ process when quenching cylindrical steel probe $50 \mathrm{~mm}$ in diameter: a) is $I Q-2$ process; b) is $I Q-3$ process.

As one can see from Figure 3, temperature difference between IQ -2 and IQ -3 processes is insignificant (see Table 9).

Table 9. Core cooling time difference between IQ-2 and IQ-3 processes when transient nucleate boiling and direct convection occur during quenching.

\begin{tabular}{llll}
\hline Temperature interval & $\mathbf{8 5 0}^{\circ} \mathbf{C}-\mathbf{5 0 0}^{\circ} \mathbf{C}$ & $\mathbf{8 5 0}^{\circ} \mathbf{C}-\mathbf{4 0 0}^{\circ} \mathbf{C}$ & $\mathbf{8 5 0}^{\circ} \mathbf{C}-\mathbf{3 0 0}^{\circ} \mathbf{C}$ \\
Cooling time for IQ -3 process in sec & 25.8 & 32.8 & 37 \\
Cooling time for IQ -2 process in sec & 27.6 & 36 & 46.8 \\
\hline
\end{tabular}

As is well known, the transient nucleate boiling process is intensive quenching by itself [4] due to acting of thousands of vapor bubbles. It should be noted here that essential effect has saturation temperature of a liquid since during transient nucleate process the surface temperature of steel can be above or below the martensite start temperature $\mathrm{M}_{\mathrm{S}}$, i.e. $T_{s f}<M_{S}$ or $T_{s f}>M_{S}$ (see Table 10) that significantly differs these two situation from each other.

Table 10. Martensite start temperature $M_{S}$ and martensite finish temperature $M_{f}$ depending on percentage of carbon in steel, C\%, wt.

\begin{tabular}{llllllll}
\hline $\mathbf{C} \%$, wt & $\mathbf{0 . 2}$ & $\mathbf{0 . 3}$ & $\mathbf{0 . 4}$ & $\mathbf{0 . 5}$ & $\mathbf{0 . 6}$ & $\mathbf{0 . 7}$ & $\mathbf{0 . 8}$ \\
\hline$M_{S},{ }^{\circ} \mathrm{C}$ & 430 & 360 & 350 & 320 & 295 & 265 & 250 \\
$M_{f},{ }^{\circ} \mathrm{C}$ & 395 & 200 & 100 & 20 & -10 & -60 & -85 \\
\hline
\end{tabular}

When performing intensive quenchi ng IQ -2 or IQ -3 processes, engineers every time must take into account martensite start temperature $M_{S}$ shown in Table 10 .

\section{Optimal Hardenability Steel}

Optimal hardenability steel was invented to provide optimal hardened layer during quenching in any cooling condition which is calculated taking into account Kondrat'ev dimensionless number $\mathrm{Kn}$. In early patented IQ - 3 technology optimal hardened layer in trough hardened steel was achieved by interruption intensive quenching at proper time using Eq. (10) [1, 21-23]:

$$
\tau=\left[\frac{k B i_{V}}{2.095+3.867 B i_{V}}+\ln \frac{T_{0}-T_{m}}{T-T_{m}}\right] \frac{K}{a K n}
$$

Here $B i_{V}=\frac{\alpha}{\lambda} K \frac{S}{V}$

$$
K n=\frac{B i_{V}}{\left(B i_{V}{ }^{2}+1.437 B i_{V}+1\right)^{0.5}}
$$


or

$$
\tau_{e q}=E_{e q} \frac{K}{a K n}
$$

Author [24] proposed a criterion which allows obtaining optimal hardened layer during cooling steel parts in any condition including cooling in low concentration of water polymer solution. Intensity of cooling in this case, as already stated, is provided by dimensionless number Kn. Optimal hardened layer during cooling in any condition is achieved if Eq. (13) is satisfied [24, 25]:

$$
\frac{D I \cdot K n^{0.5}}{D_{o p t}}=0.35 \pm 0.095
$$

Note that low hardenability steel of authors [26, 27] can be used only for extremely intensive quenching of small steel parts and cannot be used for large steel parts. Moreover, technological process is expensive and complicated. Optimal hardenability steel makes technological process very simple, cheap and it can be used for any size and form of steel part cooled in any condition. For this purpose the special software is used which was designed by Intensive Technologies Ltd. For designing such software a huge amount of experiments were carried out with water solutions of polymers to calculate dimensionless number $\mathrm{Kn}$ which is needed for optimizing chemical composition of steel using Eq. (13).

Difference between intensively quenched low hardenability steel and optimal hardenability steel quenched in any condition is shown in Figure 4 [28, 29].

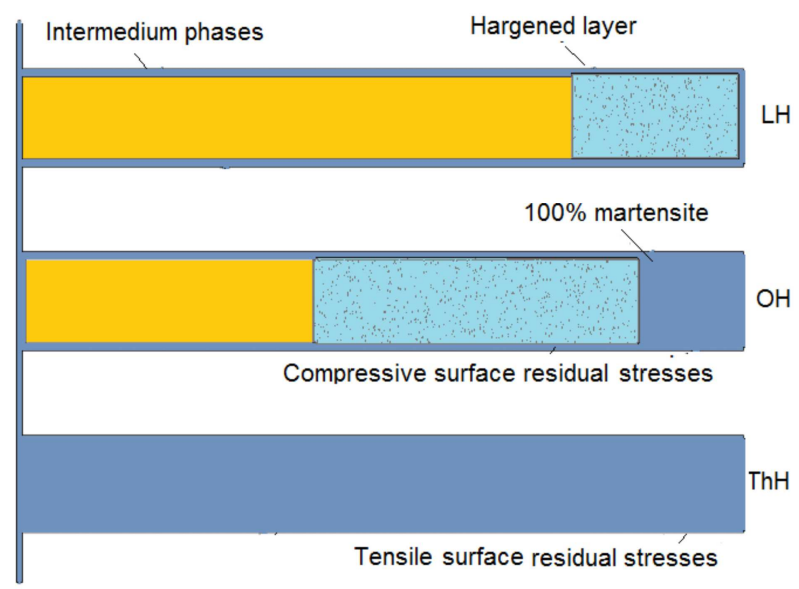

Figure 4. Optimal depth of hardened layer corresponding to the maximum surface compressive residual stresses [27]: LH, low hardenability steel; $\mathrm{OH}$, optimal hardenability; ThH, through hardening.

As one can see from Eq. (13) and Figure 4, the thickness of hardened layer proportionally increases with increasing size of steel part. The chemical composition of optimized steel for new calculated optimal hardened layer is chosen from the well know Grossmann's Eq. (14) [25]:

$$
D I=25.4 \times f_{\mathrm{Fe}} \times f_{M n} \times f_{C r} \times f_{N i} \times \ldots \ldots
$$

Effect of form of steel part on chemical composition of optimal hardenability steel is discussed in the Ukrainian Patent No. 114174 [2].

\section{Benefits Providing by Intensive Quenching of Steel in Low Concentration of Polymers}

Currently, IQ - 3 technology is successfully used in the USA $[1,4]$. However, it is rather complicated and costly and it is a reason for headache when thin holes are present in steel parts which endorse quench crack formation, especially in hardened layer. Engineers try to plug holes or use some special tricks which eliminate crack formation during quenching. But such operation makes technological process more costly and not enough convenient. Instead of costly and complicated process IQ -3 , new technology discussed in this paper, which was developed by Intensive Technologies Ltd, Kyiv, Ukraine, allows cardinally simplify technological process, make technology cardinally cheaper and repeatable During quenching steel parts with thin holes in low concentration of water polymer solutions, the thin holes are partially plugged automatically due inverse solubility phenomenon. The simple and universal quench tank for performing such operation is shown in Figure 5.

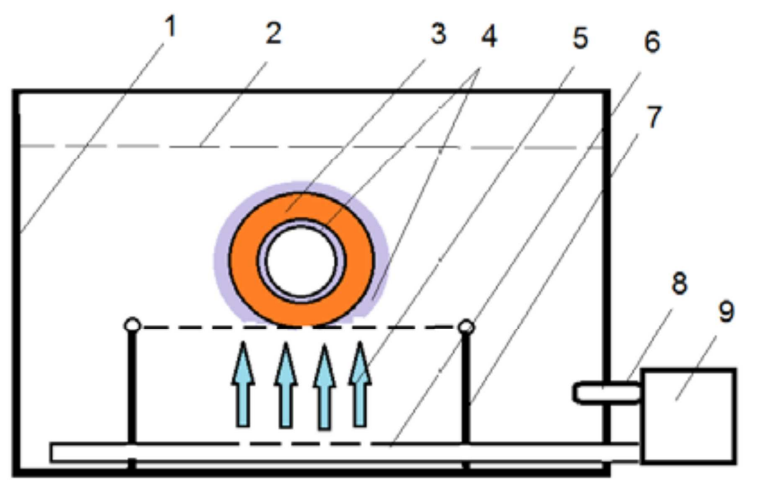

Figure 5. Prinsipal scheme of performing $I Q-2$ and $I Q-3$ processes with use of low concentration polymers: 1 is quench tank; 2 is level quenchant in a tank; 3 is steel parft (large gear or large bearing ring); 4 is surface polymeric layer; 5 is liquid stream; 6 is hydrodynamic emitter; 7 is holder; 8 is outlet tube; 9 is pump.

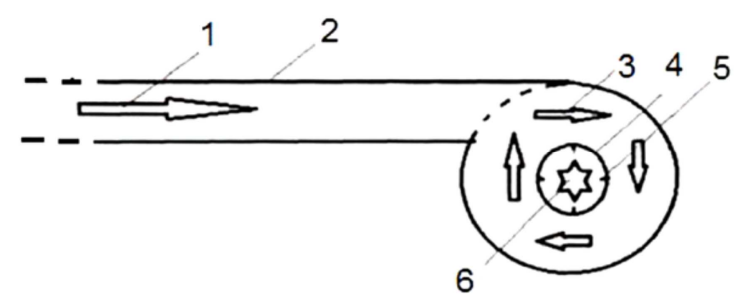

Figure 6. Schematic of the hydrodynamics emmitter generating waves in liquid with the frequency equal to the oscilating frequency of local film boiling: 1 - a water flow rate provided by the pump; $2-a$ tube, $3-a$ circulted water stream; 4 - a generator of waves in liquid; 5 - a regulator of the wave frequency; $6-a$ water flow combined with the generated waves and directed to load being quenched [3]. 
Agitation of quenchant 2 in quench tank 1 is provided by hydrodynamic emitters that generate resonance frequency to eliminate effectively the film boiling process during quenching steel parts in liquid media. Along with generating the resonance effect, pumping of liquid in quench tank creates turbulent that significantly increases heat transfer coefficients during quenching. Note that it can be used different kinds of hydrodynamic emitters which were discussed by authors [3, 28, 29]. Agitation of liquid should be not enough strong to prevent dissolving of insulating polymeric layer that eliminates film boiling process during quenching. One of mentioned emitters is shown in Figure 6 [3].

Exploring low concentration of water polymer solutions combined with the use of emitters, providing resonance waves for eliminating film boiling, it is possible to create high enough temperature gradients in quenched steel parts because transient nucleate boiling takes place. After such intensive cooling, if surface temperature of steel parts during self - regulated thermal process is below the martensite start temperature $M_{S}$, high surface compressive residual stresses are formed. As known [30], very large wind gears (see Figure 7) are made of carburized high alloy steel. It is possible to make wind gears (see Figure 7) exploring optimal hardenability steel containing $0.6 \% \mathrm{C}$, wt with significantly reduced alloy elements in it. Benefits of intensive quenching processes are provided in Table 11 and Table 12 [7, 31].

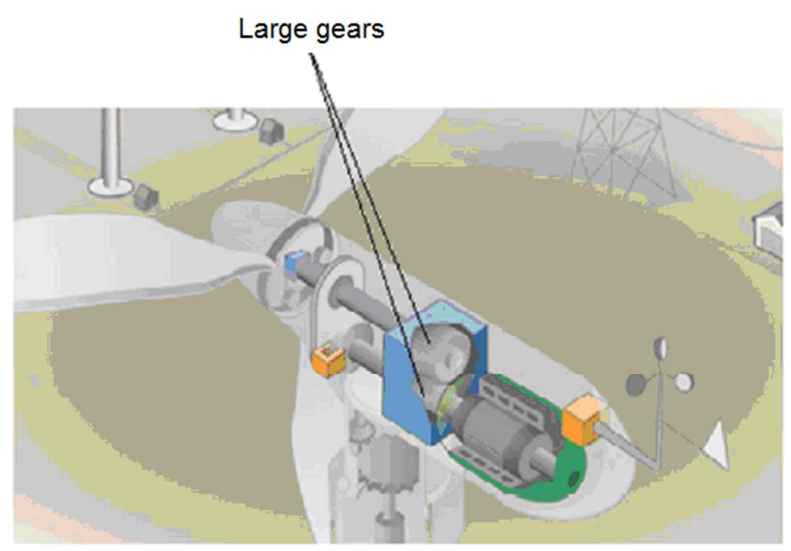

Figure 7. Typical wind mill station containing costly carburized large gears [30].

Table 11. Improvement of S5 steel punch sample properties [7].

\begin{tabular}{llll}
\hline Sample property & & Oil quench & Intensive quench \\
\hline \multirow{2}{*}{ Hardness (HRC) } & As quenched & $62-63$ & $63-64$ \\
& As tempered & $60-61$ & $60-61$ \\
Impact strength (N. m) & at $70^{\circ} \mathrm{F}$ & 1.36 & 4.08 \\
Residual Stresses (MPa) & at $100^{\circ} \mathrm{F}$ & 3.4 & 6.12 \\
\hline
\end{tabular}

Table 12. Production application of intense-quenched limited hardenability steel [29, 30].

\begin{tabular}{|c|c|c|c|}
\hline Application & Former steel and process & New steel and process & Advantages \\
\hline Gears, modulus $5-8 \mathrm{~mm}$ & $18 \mathrm{KhGT}$ carburized & $58(55 \mathrm{PP})$ no carburizing & $\begin{array}{l}\text { No carburizing steel and parts cost decreases, } \\
\text { service life increases. }\end{array}$ \\
\hline $\begin{array}{l}\text { Large modulus gears, } \mathrm{M}=10 \\
-14 \mathrm{~mm}\end{array}$ & $12 \mathrm{KhN} 3 \mathrm{~A}$ carburized & ShKh4 No carburizing & $\begin{array}{l}\text { No carburizing, service life increases } 2 \text { times and } \\
\text { cost decreases } 1.5 \text { times. }\end{array}$ \\
\hline Truck leaf springs & $60 \mathrm{C} 2 \mathrm{KhG}$ & $45 \mathrm{~S}$ & $\begin{array}{l}\text { Weight decreases } 15-20 \% \text {, durability increases } 3 \\
\text { times. }\end{array}$ \\
\hline $\begin{array}{l}\text { Bearing rings thicker that } 12 \\
\mathrm{~mm}\end{array}$ & ShKh15SG & ShKh4 & $\begin{array}{l}\text { No sudden brittle fracture in service; durability } \\
\text { increases } 2 \text { times; high production rate }\end{array}$ \\
\hline
\end{tabular}

The accurate experimental results showing essential benefits of intensively quenched steel parts made from low hardenability steel are provided in Table 12. Based on similarity theory, these benefits can be extended for larger steel parts if Eq (13) is satisfied. In this case, surface hardened layer should be thicker to provide the same surface residual stresses and supertrengthening effect after intensive quenching of larger steel parts.

Table 13 shows the benefits of new technology.

Table 13. Comparison the new and old technologies and its benefits.

\begin{tabular}{|c|c|c|c|}
\hline Name of steel part & Old technology & New technology & Benefits \\
\hline Large carburized gears & Quenching in mineral oils & $\begin{array}{l}\text { Interrupted quenching in low } \\
\text { concentration of water polymer solutions }\end{array}$ & $\begin{array}{l}\text { No costly } 70-80 \mathrm{hr} \text { carburizing process, } \\
\text { decrease corrosion and alloy elements }\end{array}$ \\
\hline $\begin{array}{l}\text { Large bearing rollers and } \\
\text { balls }\end{array}$ & $\begin{array}{l}\text { Quenching in mineral oils or } \\
\text { high concentration of water } \\
\text { polymer solutions }\end{array}$ & $\begin{array}{l}\text { Interrupted quenching in low } \\
\text { concentration of water polymer solutions }\end{array}$ & $\begin{array}{l}\text { Increase service life and significant } \\
\text { decrease of alloy elements in steel }\end{array}$ \\
\hline $\begin{array}{l}\text { Large axles and shafts made } \\
\text { of alloy and high alloy steel }\end{array}$ & Quenching in mineral oils & $\begin{array}{l}\text { Quenching in slowly agitated low } \\
\text { concentration of water polymer solutions }\end{array}$ & $\begin{array}{l}\text { Increase service life, decrease alloy } \\
\text { elements }\end{array}$ \\
\hline
\end{tabular}




\section{Discussion}

The discussed in the paper new technology is based on early published and already known to wide audience physical characteristics of transient nucleate boiling process and regularities of phase transformation austenite into martensite $[7,21,24]$. For developing new technology three patents (US patent No 6, 364, 974 B1, UA Patent 114174, and UA Patent 109572) were used to create high surface compressive residual stresses during quenching steel components in low concentration of water polymer solutions [1-3]. Transient nucleate boiling process during quenching of steel parts in water and water solutions is very intensive by itself due to high frequency and intense acting of thousands vapor bubbles $[4,5]$. The new characteristics of transient nucleate boiling process, discovered by author [17, 18], were used for designing new technology. Engineers in heat treating industry, as a rule, considered effective heat transfer coefficients during nucleate boiling which can differ from real HTCs almost ten times showing always slow cooling [15]. It was widely shared a wrong opinion that nucleate boiling cannot provide enough intensive quenching that is why very powerful and costly pumps are currently used to agitate quenchants in quench tanks. It is shown in this paper that just by destroying the film boiling process, it is possible to provide intensive quenching during hardening of steel parts. If so, the technological process become very simple and cheap that can make it widely used globally. One more thing is connected with the proposed new technology. Optimal hardenability steel provides optimal hardened layer and maximal surface compressive residual stresses even after complete cooling. In this case interruption of cooling should be made at proper time to create nano - bainitic microstructure at the core of steel parts. Nano bainitic microstructure provides additional strengthening of steel parts after quenching. This problem was discussed in the recently published paper [8]. ITL Co is developing software for governing new technological processes and is planning to organize small teams of engineers in different countries to start saving material, energy increasing service life of steel parts and decreasing cost of their production and simultaneously improving environment condition.

\section{Conclusion}

Large steel parts, beginning from thickness $50 \mathrm{~mm}(0.050$ $\mathrm{m})$ and larger, can be intensively and uniformity quenched in slowly agitated by hydrodynamic emitters of the low concentration of inverse solubility water solution polymer that eliminates completely film boiling making cooling process intensive. In this case, the high surface compressive residual stresses and superstrengthening effect in quenched steel parts are achieved due to use patented in Ukraine the optimal hardenability steel tolerated to size and form of hardened component. The proposed new technology saves materials, due to low concentration water polymer solutions and reduced percentage of alloy elements in steel, decreases corrosion due to elimination carburization process, increases service life (due to high surface compressive residual stresses and superstrengthening effect) and improves environment condition. Along with the mentioned benefits the proposed technology and equipment is much cheaper as compared with the existing IQ processes and is rather simple in its implementation in heat treating industry [32]. The new technology can bring very huge benefits. It makes sense to start worldwide testing new technology in heat treating shops of big companies worldwide.

\section{Appendix}

\begin{tabular}{|c|c|}
\hline$a$ & Thermal diffusivity of steel $\left(m^{2} s^{-1}\right)$ \\
\hline$B i_{V}$ & Generalized dimensionless Biot number \\
\hline$D$ & Diameter $(m)$ \\
\hline$R$ & Radius $(m)$ \\
\hline$D I$ & Ideal critical diameter $(m)$ \\
\hline$K$ & Kondrat'ev form coefficient $\left(m^{2}\right)$ \\
\hline$K n$ & Kondrat'ev dimensionless number \\
\hline$q$ & Heat flux density $\left(W m^{-2}\right)$ \\
\hline$q_{c r 1}$ & The first critical heat flux density $\left(\mathrm{Wm}^{-2}\right)$ \\
\hline$q_{c r 2}$ & The second critical heat flux density $\left(\mathrm{Wm}^{-2}\right)$ \\
\hline$T$ & Temperature $\left({ }^{o} C\right)$ \\
\hline $\bar{T}_{s f}$ & Average surface temperature $\left({ }^{o} C\right)$ \\
\hline $\bar{T}_{V}$ & Average volume temperature $\left({ }^{o} C\right)$ \\
\hline$T_{o}$ & Initial austenizing temperature $\left({ }^{o} C\right)$ \\
\hline$T_{S}$ & Saturation temperature $\left({ }^{o} C\right)$ \\
\hline$T_{m}$ & Bath temperature $\left({ }^{o} C\right)$ \\
\hline S & Surface $\left(m^{2}\right)$ \\
\hline $\mathrm{V}$ & Volume $\left(m^{3}\right)$ \\
\hline$v$ & Cooling rate $\left({ }^{o} \mathrm{C} / \mathrm{s}\right)$ \\
\hline $\mathrm{W}$ & Water flow speed $(m / s)$ \\
\hline$\alpha$ & Heat transfer coefficient $\left(W^{-2} K^{-1}\right)$ \\
\hline$\lambda$ & Thermal conductivity $\left(\mathrm{Wm}^{-1} \mathrm{~K}^{-1}\right)$ \\
\hline$\delta$ & Thickness of insulating layer $(\mathrm{m})$ \\
\hline$\tau$ & Time (sec) \\
\hline$\psi$ & $\begin{array}{l}\text { Criterion of temperature non -smoothness } \\
\text { through section of steel part }\end{array}$ \\
\hline
\end{tabular}




\section{List of Subscriptions}

$\begin{array}{ll}\text { coat } & \text { Coating } \\ \text { eq } & \text { Equilibrium } \\ \mathrm{nb} & \text { Nucleate boiling } \\ \mathrm{FB} & \text { Film boiling } \\ \mathrm{S} & \text { Saturation } \\ \mathrm{m} & \text { Medium } \\ \mathrm{max} & \text { Maximum } \\ \mathrm{cr} & \text { Critical } \\ \text { opt } & \text { Optimal } \\ \mathrm{sf} & \text { Surface }\end{array}$

\section{References}

[1] Kobasko, N. I. (2002) Patent US No. 6,364,974 B2, Quenching apparatus and method for hardening steel parts. Assignee: IQ Technologies, Inc Appl. 09/551,082. Filed 18.04.2000. Available at: http://patents.com/us-6364974.html.

[2] Ukrainian Patent UA 114174, C2, (2017). Alloyed Low Hardenability Steel and Method of its Composing, Filed on Sep. 23, 2013, File number: a 2013 11311, Published on June 25, 2016 in Bulletin No. 12, Legal day is May 10, 2017.

[3] Kobasko, N. I. (2015) Intensive hardening method for metal components, UA Patent, No. 109572, Published on Sept. 10, 2015, Bul. 17/2015.

[4] Tolubinsky, V. I. (1980) Teploobmen pri kipenii (Heat transfer at boiling), Naukova Dumka, Kyiv, 320 pages.

[5] Kutateladze, S. S. (1963) Fundamentals of Heat Transfer, Academic Press, New York.

[6] Shekriladze, I. G. (2012) Boiling Heat Transfer: An Overview of Longstanding and New Challenges. In a Book" Film and Nucleate Boiling Processes", K. N. Prabhu and N. Kobasko (Eds.). ASTM International, pp. 229-284.

[7] N. I. Kobasko, J. A., M. A. Aronov, J. A. Powell, G. E. Totten, G. E. (2010) Intensive Quenching Systems: Engineering and Design, ASTM International. W. Conshohocken, USA, 234.

[8] Kobasko, N. I. (2019) Optimized Steel Quenching Processes and Their New Modifications. SSRG International Journal of Applied Physics (SSRG-IJAP) - Volume 6 Issue 2 - May to August, pp. $79-86$. ISSN: 2350-0301.

[9] Kobasko, N. I. (2016) Improvement of IQ - 3 processes to eliminate crack formation, decrease distortion, and maximize material strength, and ductility. EUREKA: Physics and Engineering, Number 4, pp. 3-10. DOI: 10.21303/24614262.2016.00122.

[10] Mikheev M. A. and Mikheeva, I. M. (1977) Basics of Heat Transfer (In Russion), Energy, Moscow.

[11] Kondrat' ev, G. M. (1957) Thermal Measurements. Moscow: Mashgiz.

[12] Lykov, A. V. (1967) Theory of Heat Conductivity, Vysshaya Shkola, Moscow, 621.

[13] Kovalenko, G. V., Kobasko, N. I., Khalatov, A. A. (1987) A Method of Hardening of Steel Components. USSR Certificate
№ 1355634. Bulletin of Inventions, 44.

[14] Kobasko, N. I., Moskalenko, A. A. (1996) Intensification of steel quenching methods by use of water solutions of polymers, Promyshlennaya Teplotekhnika, Vol. 18. No. 6, pp. 55-60.

[15] Kobasko, N. I. (2012) Real and Effective Heat Transfer Coefficients (HTCs) Used for Computer Simulation of Transient Nucleate Boiling Processes during Quenching. Materials Performance and Characterization, 1 (1), MPC 2012-0012. doi: 10.1520/mpc-2012-0012.

[16] Logvynenko, P. N., Moskalenko, A. A., Kobasko, N. I., Karsim, L. O., Riabov, S. V. (2019) Oligomeric mechanism of film boiling elimination (EFB effect) during metal quenching in solutions of polyisobutylene in mineral oil, International Journal of Current Research., 11, (09), 7333-7339.

[17] Kobasko, N. I. (2009) Transient Nucleate Boiling as a Law of Nature and a Basis for Designing of IQ Technologies. Proc. of the $7^{\text {th }}$ IASME/WSEAS International Conference on Heat Transfer, Thermal Engineering and Environment (THE'09). Moscow, Aug. 20-22, pp. 67-76.

[18] Kobasko, N. I. (2012) Duration of the Transient Nucleate Boiling Process and Its Use for the Development of New Technologies, Film and Nucleate Boiling Processes (STP 1534), ASTM International, W. Conshohocken, pp. 103125 .

[19] Kobasko, N. I. (2019) Austempering Processes That are Performed via Cold Liquids, Lambert Academic Publishing, 16 p., DOI: 10.1520/mnl64-eb, ISBN: 978-620-0-11330-6.

[20] Kobasko, N. (2019) High Quality Steel vs Surface Polymeric Layer Formed during Quenching, Lambert Academic Publishing, Mauritius, $102 \mathrm{p}$.

[21] Kobasko, N. I. (1992) Intensive Steel Quenching Methods, Theory and Technology of Quenching, B. Liscic, H. M. Tensi, and W. Luty, Eds., Springer-Verlag, Berlin, pp. 367-389.

[22] Kobasko, N. I. (1980) Steel Quenching in Liquid Media Under Pressure, Naukova Dumka, Kyiv, 206 p.

[23] Kobasko, N. I. (2017) A Universal Correlation for the Calculation o f Heating and Cooling Time of Any Steel, Materials Performance and Characterization, Vol. 6, No. 1, pp. 551 - 565, DOI: 10.1520/MPC20170034.

[24] Kobasko, N. (2018) Optimal hardenability steel and method for its composing, Lambert Academic Publishing, Mauritius, $116 \mathrm{p}$.

[25] Grossmann, M. A. (1964) Principles of Heat Treatment. Ohio. American Society for metals, $302 \mathrm{p}$.

[26] Shepelyakovskii, K. Z., Ushakov, B. K. (1990) Production surface hardening - Progressive technology of XX and XXI centuries. Proc. of $7^{\text {th }}$ International Congress on Heat Treatment and Technology of Surface Coatings, Moscow, Dec. 1990, Vol. 2, pp. 11-14.

[27] Russian Patent No. 2158320 (1999) Construction Steel of Low Hardenability, Application No. 99125102, Filed on Nov. 29, 1999.

[28] Kobasko, N. I., Moskalenko, A. A., Dobryvechir, V. V. (2018) Research on use of low concentration inverse solubility polymers in water for hardening machine components and tools. EUREKA: Physics and Engineering, Number 2, pp. 63 71. DOI: $10.21303 / 2461-4262.2018 .00582$. 
[29] Kobasko, N. I. (2017) A method for optimizing chemical composition of steels to reduce radically their alloy elements and increase service life of machine components. EUREKA: Physics and Engineering, Number 1, pp. 3-12. DOI: $10.21303 / 2461-4262.2016 .00253$

[30] How do Wind Turbines Work. A New Era for Wind Power in the United States. Wind Energy Technologies Office. Available at: https://www.energy.gov/eere/wind/how-do-windturbines-work.

[31] Kobasko, N. I., Morhuniuk, W. S., Ushakov, B. K. (1992)
Design of Steel - Intensive Quench Processes. In the Steel Heat Treatment Handbook "Steel Heat Treatment (Equipment and Process Design), G. E. Totten (Ed.). CRC Press, New York, pp. 193-237.

[32] Moskalenko, A. A., Kobasko, N. I., Tolmacheva, O. V., Totten, G. E., Webster, G. M. (1996) Quechants Characterization by Acoustical Noise Analysis of Cooling Properties of Aqueous Poly (Alkylene Glycol) Polymer Quenchants. Proc. of the 2nd Int. Conf. on Quenching and Control of the Distortion, (USA), pp.117-122. 